\title{
Bonding energy and methane amount at the open surface of metamorphic coal
}

\author{
Vsevolod Vasilkovskyi ${ }^{1}$, Serhii Minieiev ${ }^{2, *}$, and Nadiia Kaluhina ${ }^{1}$ \\ ${ }^{1}$ Institute for Physics of Mining Processes of National Academy of Sciences of Ukraine, 49005, Dnipro, \\ Simferopolska Str., 2a, Ukraine \\ ${ }^{2}$ Institute of Geotechnical Mechanics named by N. Poljakov of National Academy of Sciences of \\ Ukraine, 49005, Dnipro, Simferopolska Str., 2a, Ukraine
}

\begin{abstract}
Objective of the studies is to measure and determine regularities of changes in adsorption and methane energy bond with the open surface of mineral carbons within metamorphism series. Donbas mineral carbons have been used as the samples. Volumetric method has been applied in the range of room temperatures and pressures of free methane phase (i.e. 0.015 to $3.5 \mathrm{MPa}$ ) to measure methane amount at the open surface of the mineral carbons. Depending upon changes in carbon content, adsorption behaviour is close to parabolic one: adsorption is maximal on the peripheries of metamorphic series, and minimal within its central part. For the first time, methane energy bond with the open surface of mineral carbons has been determined. In the context of the metamorphic series, bonding energy varies from 2 to $10 \mathrm{~kJ} / \mathrm{mol}$. Direct linear dependence of adsorption from pressure takes place for coal where carbon content is less than $76 \%$. It is the result of effect of large area of open surface of low-metamorphized coal. Inversely, nonlinear dependence is observed as for anthracite. The authors connect the fact with filling of all spaces at the open surface when gas phase pressure is $0.1 \mathrm{MPa}$.
\end{abstract}

\section{Introduction}

Due to the short period of physical adsorption, gas emission from solid body surface takes fractions of a second. Similar phenomenon is possible during coal-methane system reactivation or when coal is separated from a gas-bearing seam. In such a case, emission of the adsorb methane effects both level and rate of change in gas content of a face zone. In the context of coal-methane system, information is poor; thus experiments, concerning adsorption of mineral carbons, are relevant.

History of coal-methane system study makes it possible to suppose that, in general, it is reasonable to separate four types of methane state:

1) free gas in macropores and fissures;

2) condensed state in terms of volumetric filling of micropores;

3 ) adsorbed state with the formation of solid methane solution in coal;

4) adsorbed state at the coal surfaces $[1,2]$.

\footnotetext{
${ }^{*}$ Corresponding author: sergmineev@gmail.com
} 
Scientific sources throw light on the first three states. A number of publications concern methane adsorption on adsorbent coal, on multilayer carbon nanotubes, and carbon admixtures in shales [3-5]. To compare with mineral carbons, the listed materials have open sorbing surface only; thus, adsorption layer formation is not followed by diffusion introduction of gas. Scientific sources represent data, concerning adsorption of gas molecules on mineral carbon, in the form of low-temperature nitrogen sorption $[6,7]$.

Information relating to methane quantity on coal in a range of room temperatures is comparatively new $[8,9]$. That became possible after adequate measurement techniques were developed. They were tested with the use of one sample of mineral carbon; hence, in the context of the papers, the results were discussed only from the viewpoint of detalization of implementation of the methods. It is known that adsorption volume depends upon the area of open surface of the sorbent, the number of free sorbent centres, and gas energy bond with coal surface. Value of the factors varies for carbons with different metamorphism intensities; it also depends upon gas pressure. The fact has prompted the authors to determine methane energy bond with coal surface as well as adsorption volume over a wide pressure range.

Objective of the research is to define regularities concerning changes in methane adsorption volume as well as energy of its interaction with open surfaces of dry mineral carbons within metamorphism series. The paper represents the results obtained for methane from 0.015 to $3.5 \mathrm{MPa}$.

\section{Methods}

The measurements were performed with the use of methods described in [8-10]. According to the methodology, a process of helium flow and methane flow out of the known volume vessel into a capsule with coal was recorded. Pressure range was 0.015-0.095 MPa. Adsorption value was determined on the difference of volumes of the gases which have got to the capsule by the time moment $\tau$ being equal to helium flow time (i.e. $\approx 15-20 \mathrm{~s}$ ). Such a time period has been selected depending upon the fact that methane, being less viscid gas, filled the same volume of cavities within fissures and macropores as helium.

With the use of $0.9-3.5 \mathrm{MPa}$ pressure range, initial section $(\tau \approx 20-30 \mathrm{~s})$ of the compressed helium and methane flow out of a container with coal into accumulative vessel was measured and recorded. Volume difference of the gases, which have got to the vessel up to the moment of its free space filling up, was applied to determine adsorption value. Preparation method involves preliminary saturation of coal samples with the help of such compressed gases as methane and helium.

Coal from several Donbas seams with $91-79 \% C^{\mathrm{r}}$ carbon content was used as a sorbent. Samples of the milled coal in the form of $0.2-0.25 \mathrm{~mm}$ granules were dried by means of vacuum heating at $T=363 \mathrm{~K}$ temperature during $180 \mathrm{~min}$. Moisture nonavailability was controlled using Nuclear Magnetic Resonance (NMR) spectrometer. Gases, being of 99.998 purity degree, were applied for the experiments.

In terms of low pressures, specific volume of the adsorbed methane was determined on the formula:

$$
Q_{\mathrm{ads}}=V\left(\frac{P_{0}}{P_{2}}-\frac{P_{0}}{P_{1}}\right) \cdot \frac{P_{2}}{m \cdot P_{\mathrm{n}}},
$$

where $P_{\mathrm{n}}$ and $P_{0}$ - normal pressure and initial pressure within the vessel having the known volume respectively; $P_{1}$ and $P_{2}$ - helium pressure and methane pressure within the vessel by $\tau$ time moment respectively; $m$ - coal mass; and $V$ - vessel volume. 


\section{Results and discussion}

Points (०) in Figure 1 demonstrate the adsorption measurement results under $P_{2} \approx 95 \mathrm{kPa}$ pressure in the context of carbons of metamorphic series. It is understood that adsorption volume on the carbons is from $(0.05 \pm 0.02) \cdot 10^{-3} \mathrm{~m}^{3} / \mathrm{kg}$ to $(0.4 \pm 0.02) \cdot 10^{-3} \mathrm{~m}^{3} / \mathrm{kg}$.

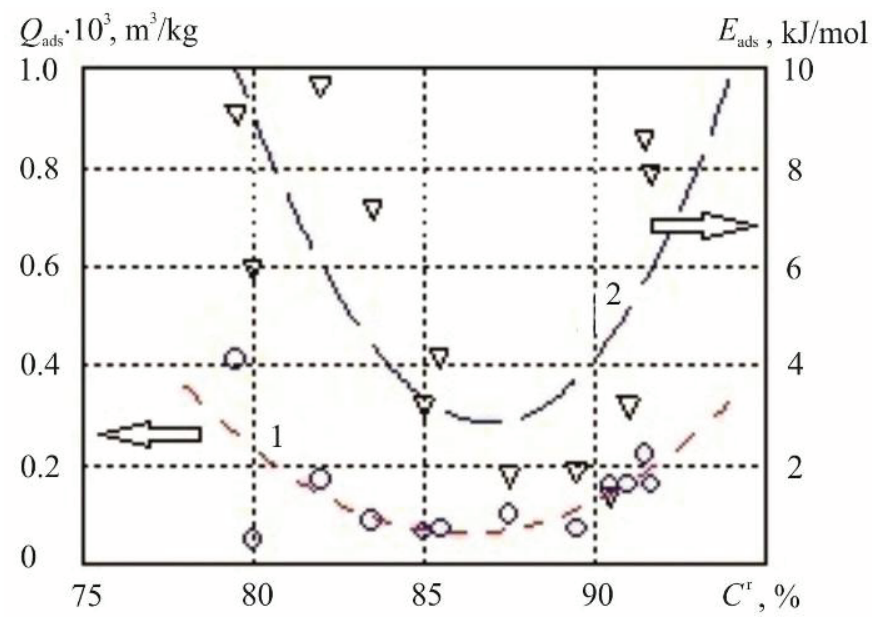

Fig. 1. Methane adsorption parameters in terms of mineral carbons with the varied content of volatile matters: $\circ$ is specific $Q_{\text {ads }}$ volume of the adsorbed methane; $\Delta$ is adsorption heat $E_{\text {ads }}$ of methane; dashed line shows curves of interpolation functions 1 and 2 with the minimum mean-square deviation from the experimental data.

Variation in $Q_{\text {ads }}$ value along with $C^{\mathrm{r}}$ carbon content variation demonstrates the minimum which may be stipulated equally by insignificant area of open coal surface, insignificant concentration of sorption centres, and comparatively poor methane energy bond with open surface of coal substance. In the context of carbons with low metamorphic intensity and anthracites, volume of methane, adsorbed at their surfaces, increases significantly (dashed line 1 corresponding to the minimum mean-square deviation from experimental data). The coal, which carbon content is $81 \%$ and $83 \%$, demonstrates itself as a material with heavy-gauge open pores providing fast access of methane molecules to a large sorbing surface. In the context of anthracite and lean coal, availability of heavy-gauge pores is scarcely probable. Thus, the increased $Q_{\text {ads }}$ adsorption for the material may be indicative of comparatively high energy of methane bond with anthracite surface. To pass from assumptions to facts, $Q_{\text {ads }}$ adsorption was analyzed in terms of other balanced pressures.

Figure 2 explains nature of $Q_{\text {ads }}$ adsorption dependence upon methane pressure $P$ for mineral carbons from several mines. Absolute error of $Q_{\mathrm{ads}}$ volume determination under small gas pressures is $\pm 0.02 \cdot 10^{-3} \mathrm{~m}^{3} / \mathrm{kg}$.

As it is seen, $Q_{\text {ads }}$ dependence upon $P$ for carbon content $\approx 82 \%$ is close to linear one. The fact can be compared from the viewpoint that coal with low metamorphic intensity has large open surface, gas access to which is provided by heavy-gauge pores and fissures. In this context, methane sorption is not sufficient to fill up all surface "seats". Conversely, in the context of anthracite, saturation effects are seen when methane pressure range is up to $0.095 \mathrm{MPa}$ : dependence of $Q_{\mathrm{ads}}$ upon $P$ is of nonlinear character being indicative of fast filling of all seats at the open anthracite surface.

Information, concerning energy of methane energy bond with the open coal surface, is of certain interest to understand physics of adsorption layer formation. Such information may be obtained while studying methane adsorption heat $E_{\text {ads }}$ on mineral carbons. 


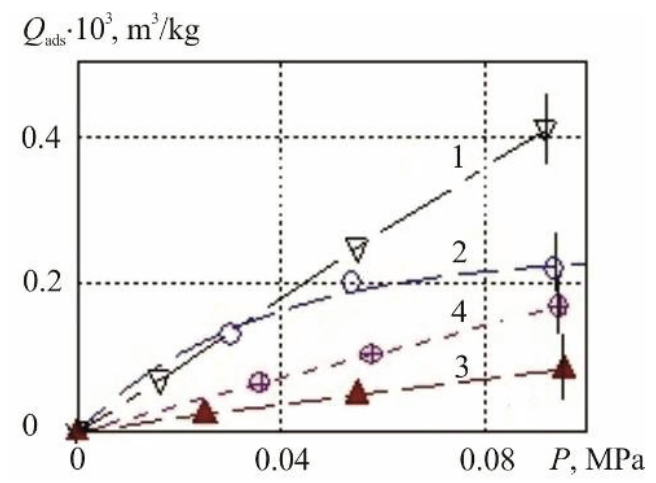

Fig. 2. Variation in the volume of methane adsorption layer $Q_{\text {ads }}$ at the open coal surfaces under the conditions of changes in $P$ pressure of gas medium within $P<0.1 \mathrm{MPa}$ range for mineral carbons with following carbon content: $80 \%-1 ; 91 \%-2 ; 84 \%-3$; and $82 \%-4$.

It is common knowledge that adsorption heat measurements can be either direct (i.e. those performed using calorimetric techniques) or indirect ones (i.e. those relying upon measuring of adsorbed volumes). To a considerable extent, adsorption value $a$ is determined with the help of $\tau$ time during which gas molecule is near the adsorbent surface. According to Fraenkel equation [11], average molecule life at the surface is $\tau=\tau_{0} \cdot \exp (E / R T)$ where $\tau_{0}$ is oscillation period of the adsorbed molecule, $R$ is absolute gas constant, and $T$ is absolute temperature. Thus, following expression is reasonable for $a$ absorption:

$$
a(T)=a_{0} \cdot \exp \left(\frac{E_{\text {ads }}}{R T}\right) .
$$

While differentiating logarithm of the expression with respect to temperature and taking $a(T)=Q_{\text {ads }}(T)$ indication, it is possible to obtain expression for numerical calculation of adsorption heat:

$$
E_{\mathrm{ads}}=\frac{R T_{1} T_{2}}{\left(T_{2}-T_{1}\right)} \ln \left[\frac{Q_{1}}{Q_{2}} \cdot \frac{P_{2}}{P_{1}}\right] .
$$

In this context, $Q_{1}$ and $Q_{2}$ are specific adsorption volumes under $P_{1}$ and $P_{2}$ pressures of gas medium, and at $T_{1}$ and $T_{2}$ coal temperatures respectively. $P_{2} / P_{1}$ multiplier is introduced into the expression to bring adsorption volumes into line with the requirement of equal pressure of gas medium.

Adsorption values and methane energy bond with the open surface of mineral carbons having different carbonization degrees were measured in terms of up to $0.1 \mathrm{MPa}$ gas pressures, and $298 \mathrm{~K}$ and $353 \mathrm{~K}$ sorbent temperatures. Figure 1 represents the measurement results $E_{\text {ads }}$ on mineral carbons ( $\Delta$ symbols). Value of methane energy bond behaviour lengthwise metamorphic series is similar to the adsorption volume; it is 2 to $10 \mathrm{~kJ} / \mathrm{mol}$. One can see that the measured $E_{\text {ads }}$ values are less than the heat being measured using NMR technique (i.e. spin-echo) as well as gravimetric measurements $(18-20 \mathrm{~kJ} / \mathrm{mol})$ [12]. That can be connected with the fact that our experiments analyzed bond with the open coal surface when the mentioned research was intended to obtain information concerning sorption heat, i.e. interaction between coal and gas molecules introduced into coal substance. It is the case when coal substance locks the gas molecules.

Figure 1 demonstrates similar type of variations in adsorption volumes, and methane energy bond with coal. The fact is explained by physics of high methane concentration near 
the coal surface. Methane adsorption depends upon bond of its molecules with coal substance which energy is characterized by absorption heat $E_{\text {ads }}$ or, in the case of the open surface, by bonding energy $E_{\mathrm{ads}}=E_{\mathrm{bond}}$ of methane molecules with sorption centres on the coal.

High and neighbour $E_{\text {bond }}$ values for anthracites and mineral carbons with low metamorphic intensity make it possible to suppose that sorption centres at the surface of such mineral carbons are of similar chemical nature. If so, then it is possible to assume inclusions of sorbing centres of another chemical nature in mineral carbons with average metamorphic intensity; their polarizing potential is much weaker.

Such an interpretation of correlation between $E_{\text {bond }}$ energy and $C^{\mathrm{r}}$ carbon content is supported by the results of analysis of coal structure macromolecules using a technique of Raman effect (RE) [13-15]. Analysis of frequency spectrum RE in anthracites has revealed structural disturbances in coal members which may induce dipole moment in methane molecules, and stimulate adsorption. Despite minor effect of carbon clusters, in the context of mineral carbons, its part is played by methyl carbon group, and methylene carbon group in aliphatic chains the listed mineral carbons are rich in.

Lower methane energy bond with mineral carbons within $84-90 \% C^{\mathrm{r}}$ interval may be stipulated by the fact that to compare with the previous case, volume of $\mathrm{C}-\mathrm{H}$ groups is decreased significantly; as a result, sorbing effect of other functional groups, containing oxygen, nitrogen, and sulphur, becomes noticeable. Perhaps, their sorption potential is quite low to compare with elements, containing carbons. That factors into the decreased average value of $E_{\text {bond }}$ parameter. Along with bond energy, the mentioned mineral carbons also differ in low natural moisture, and minimal inhibiting moisture effect on their methane content.

Information on the effect of open surface area on adsorption volume in mineral carbons has been obtained in the experiments with the use of higher pressures of gas medium. In the context of high pressure, the adsorbed methane volume was determined on the difference in methane volume and helium volume liberated from a container with coal to accumulative vessel:

$$
Q_{\mathrm{ads}}=\left.Q^{\mathrm{CH} 4}\right|_{273}-\left.F \cdot Q^{\mathrm{He}}\right|_{273} .
$$

Introduction of $F$ parameter into (4) depends upon the necessity to take into consideration Joule-Thomson effect while gas throttling as well as consideration of compressibility stipulated by pressure and temperature. To determine $F$ parameter values, adequate calculation algorithm has been developed in paper [16].

Measurements within 0.9-3.5 MPa range have shown that in the context of mineral carbons where carbon content is less than $84 \%$, dependence of $Q_{\mathrm{ads}}$ on $P$ is close to linear one in terms of the whole pressure range. It can be explained by the fact that coal with low metamorphic intensity has large open surface, gas access to which is provided by means of heavy-gauge pores and fissures. Papers $[17,18]$ also inform on the similar $Q_{\text {ads }}$ dependence upon $P$ for mineral carbons with low metamorphic intensity.

Figure 3 demonstrates estimation results of methane adsorption value on metamorphic series of mineral carbons at $298 \mathrm{~K}$ temperature and under 3.0 MPa saturation pressure.

It is understood that along with carbon content increase, adsorption volume experiences more than 10 times decrease. Methane adsorption value on the surface of coal containing $82 \%$ comes under notice since it is $(9 \pm 0.6) \cdot 10^{-3} \mathrm{~m}^{3} / \mathrm{kg}$. It may seem erroneous at a first glance because it is common knowledge that daily average gas content of the mine is not more than $7 \cdot 10^{-3} \mathrm{~m}^{3} / \mathrm{kg}$. The inadequacy comes from the fact that we use dry coal and under natural conditions its moisture content is $13 \%$. It is the moisture being available in coal that reduces its gas content. 


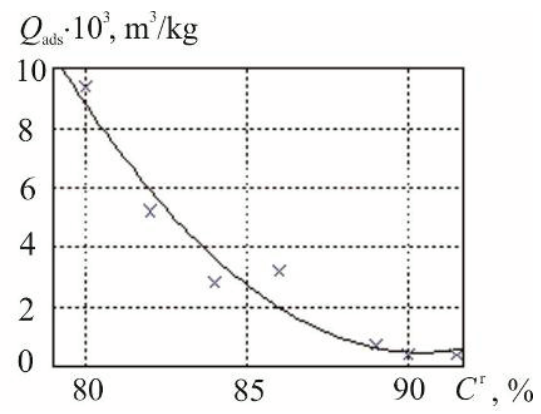

Fig. 3. Specific volume of methane adsorption at the open surface of mineral carbons of metamorphic series: $x$ - the results of experimental measurements.

\section{Conclusions}

1. Regularity of methane energy bond variation has been determined as well as adsorption volume at the surface dry mineral carbons of metamorphic series over room temperature range when methane pressure is more than $0.1 \mathrm{MPa}$ or less than it. It has been defined that under low pressure, being less than $0.1 \mathrm{MPa}$, adsorption volume correlates with methane energy bond with the coal surface. It means that methane energy bond with the open coal surface is the basic parameter stipulating adsorption value.

2. In the context of high pressures (i.e. those being more than $0.1 \mathrm{MPa}$ ), absorption behaviour cannot correlate directly with methane-coal energy bond. Correlation starts to be seen only in the context of mineral carbons which carbon content is less than $86 \%$. It is possible if only sorbing surface is large.

3. It has been identified that if carbon content is less than $86 \%$, adsorption increase, along with the methane pressure growth, is of linear nature with no features of the adsorbed layer saturation. On the contrary, anthracites demonstrate initial saturation characteristics when pressure range is up to $0.1 \mathrm{MPa}$ which means that the open surface is small.

4. Comparison of the obtained results with data concerning sorption characteristics of natural-moisture mineral carbons shows that use of hydrotreating methods is the most expedient and efficient one in the context of coal seams being of average metamorphic intensity.

\section{References}

1. Alekseiev, A.D. (2010). Fizika uglia i gornyh protsessov. Kiev: Naukova Dumka

2. Mineiev, S.P. (2007). Aktivatsiia desorbtsii metana v ugolnyh plastah. Dnepropetrovsk: Weber

3. Zou, J., Rezaee, R., Liu, K. (2017). Effect of Temperature on Methane Adsorption in Shale Gas Reservoirs. Energy Fuels, 31, 12081-12092

4. Delavar, M., Ghoreyshi, A.A., Jahanshahi, M. Comparative experimental study of methane adsorption on multi-walled carbon nanotubes and granular activated carbon. Journal of Experimental Nanoscience, 9, 3, (2014)

5. Mineiev, S.P. (2009). Svoistva gazonasyshchennogo uglia. Dnipropetrovsk: NGU

6. Ettinger, I. L., Shulman, N.V. (1975). Raspredelenie metana v porah iskopaemyh uglei. Moskva: Nauka

7. H. Gan, S.P. Nandi, P.L. Walker Jr., Nature of the porosity in American coals. Fuel, 51 4 (1972)

8. Vassilkovki, V.A. (2011). The amount of methane on the surface of coal. 
Gornospasatelnoe delo: sbornik nauchnyh trudov, 45-52

9. Alekseiev, A.D., Vassilkovki, V.A., Shazhko, Ya.V. (2007). About the distribution of methane in coal. Fiziko-tehnicheskie problemy gornogo proizvodstva: sbornik nauchnyh trudov, 10, 29-38

10. Vassilkovki, V.A., Mineiev, S.P. (2017). Distribution and mechanism of movement of methane in coal blocks. Fiziko-tehnicheskie problemy gornogo proizvodstva: Sbornik naukovyh prats, 19, 19-33

11. Fraenkel, Ya. I. (1975). Kineticheskaia teoria zhidkostei. Leningrad: Nauka

12. Vassilenko, T.A., Kirillov, A.K., Molchanov, A.N. (2013) Effect of humidification on the energy of methane bond with coal. Naukovi pratsi UkrNDMI NAN Ukainy, 13 (1), 174-182

13. S. Potgieter-Vermaak, N. Maledi, N. Wagner, Raman spectroscopy for the analysis of coal: a review. Journal of Raman Spectroscopy, 42, 2 (2011)

14. Alekseiev, A.D., Ulianova, E.V., Trachevski, V.V. (2010). Application of raman scattering and nuclear magnetic resonance methods for the study of the genesis of the structure of carbon nanomaterials of natural origin. Fizika i tehnika vysokih davlenii, 20 (3), 126-139

15. Alekseiev, A.D., Ulianova, E.V., Vassilkovski, V.A., Razumov, O.N., Zimina, S.V., Skoblik, A.P. (2010). Features of the coal structure of the ejection zone. Gorny informatsionno-analiticheskii bulleten, 8, 164-179

16. Vassilkovski, V.A., Dovbnich, M.M., Mendrii, Ya.V. (2016). Adsorption of methane in fossil coals in the range of room temperatures and pressures higher 0.1MPa. Fizika $i$ tehnika vysokih davlenii, 26 (3-4), 79-88

17. X. Li, X. Fu, A. Liu, Methane Adsorption Characterisnics and Adsorbed Gas Content Low-Rank Coal in China, Energy Fuels, 30, (2016)

18. Bulat, A.F., Mineev, S.P., Prusova, A.A. (2016). Generating methane adsorption under relaxation of molecular structure of coal. Journal of Mining Science, 52 (1), 70-79 